\title{
THE PREVENTION OF ANAEMIA OF PREMATURITY
}

\author{
BY \\ W. D. ELLIOTT \\ From the St. Mary's Hospitals for Women and Children, Manchester
}

(RECEIVED FOR PUBLICATION OCTOBER 30, 1961)

As a result of a clinical trial carried out in these hospitals (Gaisford and Jennison, 1955), which showed that the intramuscular administration of an iron-dextran complex to premature babies in the newborn period could effectively prevent the anaemia of prematurity, iron by this route was given to babies in the premature baby unit, whose haemoglobin levels fell below $80 \%(11 \cdot 7 \mathrm{~g}$.) before their discharge from the unit.

Early in 1960, when it was reported that the intramuscular preparation of iron in common use might carry a risk of tumour production at the site of injection (Brit. med. J., 1960), this practice was stopped and oral iron was prescribed during the follow-up of the premature babies.

The purpose of this paper is to compare the results of the prophylactic administration of intramuscular or oral iron preparations with those in a group of babies who received neither.

The progress of babies nursed in the premature baby unit is followed, after their discharge from hospital, in a special clinic at which some premature babies nursed in the ordinary newborn nurseries of the hospital and some born outside hospital are also seen. At each visit to this clinic all babies have a haemoglobin estimation carried out on capillary blood from a heel stab. The haemoglobin level is measured as oxyhaemoglobin in an EEL photoelectric colorimeter, standardized so that $100 \%$ represents $14.6 \mathrm{~g}$. $\mathrm{Hb} / 100 \mathrm{ml}$. As most of these babies attend at intervals of a month or less up to the age of 6 months, estimations of their haemoglobin levels have been obtained from month to month during that period.

\section{Material}

202 babies whose birth weights were below $5 \mathrm{lb} .(2 \cdot 26 \mathrm{~kg}$. $)$ were included in the series. Table 1 shows their distribution in the three treatment groups according to birth weight.

The intramuscular iron preparation used in the premature nursery was an iron-dextran complex (Imferon). The dose of elemental iron varied between 50 and $250 \mathrm{mg}$., depending in most cases upon the haemoglobin level at the time, but was generally $100 \mathrm{mg}$. contained in $2 \mathrm{ml}$. of the preparation, $1 \mathrm{ml}$. being injected into each buttock.

The routine oral preparation was a mixture containing ferrous sulphate gr. 1 given thrice daily, starting before the sixth week of life. In the few babies who appeared to be intolerant of this preparation other oral iron preparations were used.

At the time when intramuscular iron was in use oral preparations were not given as a routine, but many of the 'no treatment' group were given oral iron after the twelfth week when their haemoglobin levels fell below $65 \%$.

In order to compare the three groups mean haemoglobin levels have been calculated in each group at four-week intervals from birth to 32 weeks. Should a baby have had more than one haemoglobin estimation during any four-week period the average value has been calculated and the resulting figure used in the final calculation for the group.

\section{Results}

Table 2 shows the mean haemoglobin levels of treated and untreated groups at each four-week period from birth to 32 weeks.

The results are shown graphically in Fig. 1.

\section{Discussion}

It is quite clear that the babies receiving intramuscular iron responded better than the others in the two smaller birth weight groups and did as well as those receiving oral iron in the 4 to under $5 \mathrm{lb}$.

TABLE 1

\begin{tabular}{|c|c|c|c|c|}
\hline \multirow{2}{*}{ Treatment Group } & \multicolumn{3}{|c|}{ Birth Weight } & \multirow{2}{*}{ Totals } \\
\hline & 2 to $<3 \mathrm{lb}$. & 3 to $<4$ lb. & 4 to $<5 \mathrm{lb}$ & \\
\hline $\begin{array}{l}\text { Intramuscular iron .. } \\
\text { Oral iron ... } \\
\text { No treatment }\end{array}$ & $\begin{array}{r}13 \\
9 \\
0\end{array}$ & $\begin{array}{l}35 \\
25 \\
18\end{array}$ & $\begin{array}{r}9 \\
41 \\
52\end{array}$ & $\begin{array}{l}57 \\
75 \\
70\end{array}$ \\
\hline Totals ... & 22 & 78 & 102 & 202 \\
\hline
\end{tabular}



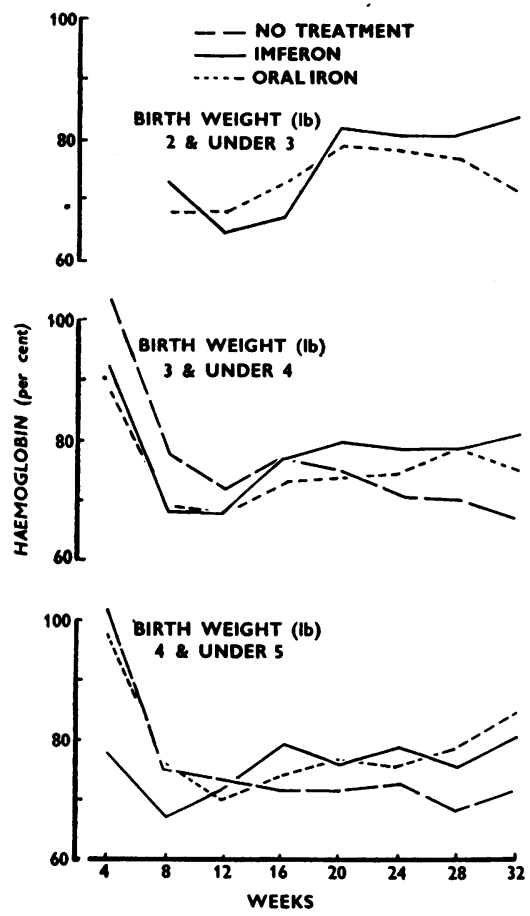

Fig. 1.

group. In the 2 to under $3 \mathrm{lb}$. birth weight group oral iron is significantly less effective than intramuscular iron, the maximum rise in mean haemoglobin level being $11 \%$ as compared with $19 \%$. This may be due to an inherent weakness in oral iron therapy, namely that one can never be certain that mothers are giving their babies the preparation regularly. It was common to find that a mother who had been given a month's supply of iron mixture returned to the clinic at the end of that month with the bottle still half full.

Although the establishment of mixed feeding at 3 months has been actively encouraged in every baby, whatever his birth weight, this early introduction of an iron-rich diet has not prevented the steady decline in haemoglobin levels in babies not receiving prophylactic iron. The figures in Table 2 and the graphs do not truly reflect this, because 25 of the 70 babies in the 'no treatment' group were given oral iron as a therapeutic measure at some time after 12 weeks of age.

A comparison of results in the intramuscular iron groups between babies given more than $100 \mathrm{mg}$. of iron and those given $100 \mathrm{mg}$. or less shows that the smaller doses are as effective as the larger in preventing anaemia.

\section{Conclusions}

All premature babies require additional iron if they are not to become anaemic during the first year of life. Even a satisfactory mixed diet started in the fourth month will not prevent this anaemia, though it may possibly maintain a satisfactory haemoglobin level if additional iron has previously been given.

In most cases the regular administration of any standard oral preparation of iron is sufficient to prevent the anaemia, though there are inevitably some mothers who, through forgetfulness or unwillingness for some reason, fail to administer the oral preparation regularly.

Imferon given in the newborn period in an equivalent dose of $100 \mathrm{mg}$. of elemental iron prevents the anaemia of prematurity without the necessity for further therapy provided that mixed feeding is started during the fourth month of life. The cost of this treatment is, in fact, less than the total cost of dispensing even the cheapest oral preparations during the first six months of the baby's life.

\section{Summary}

A comparison of mean haemoglobin levels at four-week intervals between 57 premature babies who received intramuscular injections of an iron-

TABLE 2

\begin{tabular}{|c|c|c|c|c|c|c|c|c|c|c|c|}
\hline \multirow{2}{*}{\multicolumn{2}{|c|}{ Treatment }} & \multirow{2}{*}{$\begin{array}{l}\text { Birth } \\
\text { Weight } \\
\text { Group }\end{array}$} & \multirow{2}{*}{ No. } & \multicolumn{8}{|c|}{ Four-week Periods From Birth to 32 Weeks (Mean Hb \%) } \\
\hline & & & & 1 & 2 & 3 & 4 & 5 & 6 & 7 & 8 \\
\hline Intramuscular iron & $\cdots$ & $\begin{array}{l}2 \text { to }<3 \mathrm{lb} \text {. } \\
3 \text { to }<4 \mathrm{lb} \text {. } \\
4 \text { to }<5 \mathrm{lb} \text {. }\end{array}$ & $\begin{array}{r}13 \\
35 \\
9\end{array}$ & $\begin{array}{l}\overline{92} \\
78\end{array}$ & $\begin{array}{l}73 \\
68 \\
67\end{array}$ & $\begin{array}{l}65 \\
68 \\
72\end{array}$ & $\begin{array}{l}67 \\
77 \\
79\end{array}$ & $\begin{array}{l}82 \\
80 \\
76\end{array}$ & $\begin{array}{l}81 \\
79 \\
79\end{array}$ & $\begin{array}{l}81 \\
79 \\
76\end{array}$ & $\begin{array}{l}84 \\
81 \\
81\end{array}$ \\
\hline Oral iron & $\cdots$ & $\begin{array}{l}2 \text { to }<3 \mathrm{lb} \text {. } \\
3 \text { to }<4 \mathrm{lb} \text {. } \\
4 \text { to }<5 \mathrm{lb} \text {. }\end{array}$ & $\begin{array}{r}9 \\
26 \\
41\end{array}$ & $\begin{array}{l}\overline{89} \\
98\end{array}$ & $\begin{array}{l}68 \\
69 \\
76\end{array}$ & $\begin{array}{l}68 \\
68 \\
70\end{array}$ & $\begin{array}{l}73 \\
73 \\
74\end{array}$ & $\begin{array}{l}79 \\
74 \\
77\end{array}$ & $\begin{array}{l}78 \\
75 \\
76\end{array}$ & $\begin{array}{l}77 \\
79 \\
79\end{array}$ & $\begin{array}{l}72 \\
75 \\
85\end{array}$ \\
\hline No treatment & $\cdots$ & $\begin{array}{l}2 \text { to }<3 \mathrm{lb} \text {. } \\
3 \text { to }<4 \mathrm{lb} \text {. } \\
4 \text { to }<5 \mathrm{lb} \text {. }\end{array}$ & $\begin{array}{r}0 \\
18 \\
52\end{array}$ & $\begin{array}{l}\overline{104} \\
102\end{array}$ & $\begin{array}{l}\overline{78} \\
75\end{array}$ & $\begin{array}{l}\overline{72} \\
73\end{array}$ & $\begin{array}{l}\overline{77} \\
72\end{array}$ & $\begin{array}{l}\overline{75} \\
72\end{array}$ & $\begin{array}{l}\overline{71} \\
73\end{array}$ & $\begin{array}{l}\overline{70} \\
69\end{array}$ & $\begin{array}{l}\overline{67} \\
72\end{array}$ \\
\hline
\end{tabular}


dextran complex in the newborn period, 75 who received oral iron during the first six months of life and 70 who did not receive any prophylactic iron indicates that the intramuscular preparation was the most effective in preventing the anaemia of prematurity, especially in the babies of lowest birth weight. It is suggested that oral iron might be satisfactory if its regular administration could be assured.

It is also suggested that the introduction of mixed feeding in the fourth month of life may help to maintain a satisfactory haemoglobin level once this has been achieved by the administration of additional iron, but will do no more than check the rate of fall in haemoglobin level if additional iron is not given.

I am grateful to Professor Wilfrid Gaisford for his advice and encouragement, and to the Department of Medical Illustration, Manchester Royal Infirmary, for help in preparing the graphs.

\section{REFERENCES}

Brit. med. J. (1960). Leading article. Carcinogenic risks of irondextran 1,788 .

Gaisford, W. and Jennison, R. F. (1955). Intramuscular iron in infancy. Brit. med. J., 2, 700. 